\title{
Vaginal cuff brachytherapy in endometrial cancer - a technically easy treatment?
}

This article was published in the following Dove Press journal:

Cancer Management and Research

9 August 2017

Number of times this article has been viewed

\author{
Sebastià Sabater ${ }^{\prime}$ \\ Ignacio Andres' \\ Veronica Lopez-Honrubia' \\ Roberto Berenguer' \\ Marimar Sevillano' \\ Esther Jimenez-Jimenez ${ }^{2}$ \\ Angeles Rovirosa ${ }^{3}$ \\ Meritxell Arenas ${ }^{4}$ \\ 'Department of Radiation Oncology, \\ Complejo Hospitalario Universitario \\ de Albacete, Albacete, ${ }^{2}$ Department \\ of Radiation Oncology, Hospital \\ Son Espases, Palma de Mallorca, \\ ${ }^{3}$ Department of Radiation Oncology, \\ Hospital Clinic, Barcelona, \\ ${ }^{4}$ Department of Radiation Oncology, \\ Hospital Universitari Sant Joan, Reus, \\ Spain
}

\begin{abstract}
Endometrial cancer (EC) is one of the most common gynecological cancers among women in the developed countries. Vaginal cuff is the main location of relapses after a curative surgical procedure and postoperative radiation therapy have proven to diminish it. Nevertheless, these results have not translated into better survival results. The preeminent place of vaginal cuff brachytherapy (VCB) in the postoperative treatment of high- to intermediate-risk EC was given by the PORTEC-2 trial, which demonstrated a similar reduction in relapses with VCB than with external beam radiotherapy (EBRT), but VCB induced less late toxicity. As a result of this trial, the use of VCB has increased in clinical practice at the expense of EBRT. A majority of the clinical reviews of VCB usually address the risk categories and patient selection but pay little attention to technical aspects of the VCB procedure. Our review aimed to address both aspects. First of all, we described the risk groups, which guide patient selection for VCB in clinical practice. Then, we depicted several technical aspects that might influence dose deposition and toxicity. Bladder distension and rectal distension as well as applicator position or patient position are some of those variables that we reviewed.
\end{abstract}

Keywords: endometrial cancer, vaginal cuff brachytherapy, rectum, bladder, technique

\section{Introduction}

Endometrial cancer (EC) is a leading cause of female cancer in developed countries. It is the fifth most common cancer worldwide in women. Approximately $40 \%$ of EC is diagnosed in Europe, representing the fourth neoplasm among women and the third gynecological cancer after breast and ovarian cancers. ${ }^{1}$ The annual incidence in developed countries varies from 12.9 to 15.6 per 100000 women in the European countries and up to 19.1 per 100000 women in the US, while these figures drop to $<5$ per 100000 women in Africa and 2.7 in South-Central Asia. ${ }^{2}$

Most EC is diagnosed in its early stages due to the promptness of symptoms, mainly postmenopausal vaginal bleeding. The cornerstone of treatment, after metastases are ruled out, is surgery, which aside from its curative nature is the main staging procedure, and postoperative irradiation is added for patients at risk of relapse. ${ }^{3}$ The majority of EC patients have low-to-intermediate-risk (55\%) or high-to-intermediate-risk (30\%) tumors; only $15 \%$ of patients have high-risk tumors. ${ }^{3}$ Patient selection for adjuvant treatment depends on the clinicopathological factors of risk and the type of surgery undertaken. ${ }^{3}$ Brachytherapy has, since 1903, been a well-established radiotherapy technique to treat cancer in several locations, such as the prostate, penile, skin and head-and-neck tumors, in addition to gynecological tumors. ${ }^{4-7}$
Correspondence: Sebastià Sabater Department of Radiation Oncology, Complejo Hospitalario Universitario de Albacete, C/Hnos Falcó 37, 02006 Albacete, Spain

Tel +34967597523

Fax +34967597530

Email ssabaterm@gmail.com 
While the current standard surgical management for early EC clearly involves a total hysterectomy with bilateral salpingo-oophorectomy, the role of lymphadenectomy is controversial at the moment and its practice varies worldwide. Pelvic lymphadenectomy or multiple site sampling remains the standard procedure in many departments except for patients at high risk of surgical morbidity. Para-aortic lymphadenectomy is more controversial besides its use on high-risk patients with high-grade or stage II tumors. Despite single-center and retrospective reports having reported lymphadenectomy benefits, ${ }^{8,9}$ randomized trials have failed to demonstrate an overall or a progression-free survival advantage. ${ }^{10,11}$ In addition, low-risk disease patients have not benefited from this procedure, ${ }^{12}$ which is associated with $8 \%-50 \%$ of lymphedema. In any case, lymphadenectomy has shown benefits as a staging procedure. Laparoscopic surgery improves patient recovery compared with the laparotomic approach. ${ }^{13}$ The LAP2 study ${ }^{14}$ demonstrated a significant reduction in moderate-to-severe postoperative adverse complications of the laparoscopy compared to the laparotomy ( $14 \%$ vs $21 \%$ ) despite the longer operation time (mean, 204 vs 130 minutes). In all, 25.8\% of the patients assigned to laparotomy required conversion to laparotomy. Significantly, pelvic and para-aortic nodes were not removed in $8 \%$ of laparoscopic patients compared to $4 \%$ of laparotomy patients. A step forward in reducing surgical morbidity further has been the removal of selective sentinel lymph nodes. The FIRES trial ${ }^{15}$ successfully mapped at least one sentinel lymph node in $86 \%$ of patients. No lymph node metastases were identified in $3 \%$ of patients with node-positive disease. Sensitivity and negative predictive values were of $97.2 \%$ and $99.6 \%$, respectively.

Recurrence following initial treatment appears in 10-13\% of patients; $>70 \%$ of failures appear in the vagina but an extrapelvic failure can be detected in $>75 \%$ of the relapsed patients. ${ }^{16}$ Hematogenous metastases have been reported in $6-10 \%$ of patients, ${ }^{17}$ the lungs being the most common site (2-8\% of EC patients). A review carried out in Poland of 1610 patients found 134 hematogenous metastases in 110 patients with stages I and II. Sites of metastases were the lungs (69 metastases), liver (32 metastases), bones (23 metastases) and brain (10 metastases). ${ }^{18}$ These figures can increase up to $24 \%$ in patients with unfavorable histologies, such as clear-cell (CC) carcinoma. ${ }^{19} \mathrm{~A}$ total of $10 \%$ of patients who died from their EC had disease in the pelvis, $37 \%$ had in the abdomen (liver metastases accounted for $35 \%$ of these) and $53 \%$ had at distant places (lungs hosted metastases in 78\% of these patients). ${ }^{20}$ Prospective studies have demonstrated a decrease in local relapses with postoperative radiotherapy, either external beam radiotherapy (EBRT) or vaginal cuff brachytherapy (VCB), but results have not translated to a survival advantage. Nevertheless, these randomized studies have not been powerful enough to detect it. Analyses of the large National Cancer Database (NCDB), which collects data from $>1500$ facilities in the US, showed a survival benefit among patients at high-to-intermediate-risk and high-risk patients treated with postoperative radiotherapy. ${ }^{21}$ The analyses of $>132000$ patients showed up to a $22 \%$ decrease in mortality risk in these patient groups, and postoperative irradiation was an independent factor for overall survival in a multivariate analysis. Data from the Surveillance, Epidemiology, and End Results (SEER) database have shown an improvement in survival with EBRT or VCB among intermediate- patients and high-risk patients without lymph node dissection, ${ }^{22,23}$ but a further analysis of 58.172 patients included in the SEER database failed to demonstrate an improvement in cancerspecific mortality. ${ }^{24}$ Additionally, smaller population-based reports, like the Danish population-based study, also failed to demonstrate improvement in survival. ${ }^{25}$ These doubts about survival have raised the need for evaluating the costs of VCB. Postoperative VCB cost for intermediate-risk EC patients was USD 38764/life saved, ${ }^{26}$ which is less than the value generally considered the acceptable cutoff for intervention (USD 50000/life saved).

Owing to the increasing trend for using VCB, reported from the SEER data, ${ }^{27}$ it is a good idea to describe patient selection and technical issues related with VCB in EC, some of which are not usually addressed. The manuscript is focused on high-dose rate (HDR) because nowadays only $3.8 \%$ of the US radiation oncologists use low-dose rate (LDR). VCB reviews usually summarize patient selection and group description because VCB is regarded as a simple and easy technique that is generally well tolerated.$^{28}$ Instead, we dealt in-depth with patient and technical issues, not usually covered in other critical reviews, such as body mass index, patient position, applicator position or rectum and bladder filling, among others. ${ }^{29-33}$ Several of these issues have not been covered in the recent American Brachytherapy Task Group Report. ${ }^{34}$

\section{Patient selection and risk groups}

Clinicopathological findings define the risk for disease relapse and guide indications for postoperative treatments. Indications include age, International Federation of Gynecology and Obstetrics (FIGO) stage, histological type, depth of myometrial invasion, pathological grade and lymphovascular space 
invasion (LVSI), and some guidelines add tumor size to this list when recommending adjuvant radiation. Several risk groups have been proposed that do not match completely (Table 1). American Society for Radiation Oncology (ASTRO)/ American Society of Clinical Oncology (ASCO) guidelines provide the simpler definition of a high-to-intermediate-risk group. ${ }^{35}$ In a randomized trial of low-risk patients, only $4 \%$ of the overall group relapsed, suggesting that they would not benefit from adjuvant irradiation. ${ }^{36}$ Intermediate-risk patients, however, can benefit from postoperative radiotherapy. Three large randomized trials ${ }^{10,37,38}$ have demonstrated a reduction in pelvic and local relapses, $70 \%$ of which appear in the vaginal vault, and failed to improve survival (Table 2). A Cochrane meta-analysis determined that EBRT produced an absolute risk reduction of locoregional recurrences of $6 \%$, meaning that one locoregional relapse is prevented in every 16.7 treated patients. ${ }^{39}$ Sorbe et $\mathrm{al}^{40}$ also have demonstrated that VCB provides similar tumor control than EBRT at lower toxicity and, thus, a better quality of life. The VCB arm was associated with significantly less diarrhea, fecal leakage, need of the toilet and less limitation in daily activities. Table 3 shows the National Comprehensive Cancer Network (NCCN) guidelines for postoperative radiotherapy. Irradiation in stage III/IV has been less studied; a retrospective SEER analysis of 1577 patients demonstrated higher 5-year overall survival with the addition of EBRT or EBRT + VCB (surgery $40 \%$, EBRT 56\%, EBRT + VCB 65\%). ${ }^{41}$ Results from the NCDB have shown that VCB improves survival among women with stage IA. ${ }^{42}$ Results from the same database show that the addition of VCB to EBRT improves survival in stage III patients with cervical involvement (hazard ratio 0.86). ${ }^{43}$ Results from the SEER database show that among stage I patients graded into PORTEC-risk groups, there is a significant improvement in survival in high-to-intermediate- and high-risk patients irrespective of the irradiation technique. ${ }^{21}$ Analysis of this database also shows an improvement in survival with

Table I Risk group descriptions in the different definitions

\begin{tabular}{|c|c|c|c|c|}
\hline \multirow[t]{2}{*}{ Study } & \multicolumn{4}{|l|}{ Risk group } \\
\hline & Low & Intermediate & High-to-intermediate & High \\
\hline PORTEC-I ${ }^{37}$ & GI-2, <50\% MI, EC & $\begin{array}{l}\text { Stage I, EC } \\
\text { - } \mathrm{GI} \text { and } \geq 50 \% \mathrm{MI} \\
\text { - } \mathrm{G} 2 \\
\text { - } \mathrm{G} 3 \text { and }<50 \% \mathrm{MI}\end{array}$ & $\begin{array}{l}\text { EC with at least } 2 / 3 \text { factors } \\
>60 \text { years } \\
\text { - } \mathrm{G} 3 \\
\text { - } \geq 50 \% \mathrm{MI}\end{array}$ & $\begin{array}{l}\text { Stages III-IV } \\
\text { Uterine serous or CC } \\
\text { carcinoma, any stage }\end{array}$ \\
\hline PORTEC-2 ${ }^{44}$ & & & $\begin{array}{l}>60 \text { years } \\
\text { - Stage IC + GI-2 } \\
\text { - Stage IB + G3 } \\
\text { Stage IIA (excluded }>50 \% \text { MI } \\
+ \text { G3) }\end{array}$ & \\
\hline GOG-9938 & Stage IA, GI-2, endometrioid & $\begin{array}{l}\leq 50 \text { years and } \leq 2 \text { PRF* }^{*} \\
50-69 \text { years and } \leq 1 \text { PRF* } \\
\geq 70 \text { years and no PRF* }\end{array}$ & $\begin{array}{l}\text { Any age and } 3 \mathrm{PRF}^{*} \\
50-69 \text { years and } \geq 2 \mathrm{PRF}^{*} \\
\geq 70 \text { years and } \geq 1 \mathrm{PRF}^{*}\end{array}$ & $\begin{array}{l}\text { Stages III-IV, any histology or } \\
\text { grade } \\
\text { Uterine serous or CC } \\
\text { carcinoma, any stage }\end{array}$ \\
\hline ESMO $2013^{58}$ & $\begin{array}{l}\text { Stages IA-IB endometrioid } \\
\text { No LVSI }\end{array}$ & $\begin{array}{l}\text { Stage IA, G3, endometrioid } \\
\text { Stage IB, GI-2, endometrioid }\end{array}$ & & $\begin{array}{l}\text { Stage IB, G3, endometrioid } \\
\text { Non-endometrioid, all stages }\end{array}$ \\
\hline ESMO $2016^{114}$ & $\begin{array}{l}\text { Stage I endometrioid } \\
\text { - GI-2 } \\
\text { - }<50 \% \text { MI } \\
\text { - No LVSI }\end{array}$ & $\begin{array}{l}\text { Stage I endometrioid } \\
\text { - GI-2 } \\
\text { - } \geq 50 \% \mathrm{MI} \\
\text { - No LVSI }\end{array}$ & $\begin{array}{l}\text { Stage I endometrioid } \\
\begin{array}{l}-\mathrm{G} 3 \\
\text { - }<50 \% \mathrm{MI} \\
\text { - Regardless of LVSI status }\end{array}\end{array}$ & $\begin{array}{l}\text { Stage I endometrioid } \\
-\mathrm{G} 3 \\
-\geq 50 \% \mathrm{MI} \\
- \text { Regardless of LVSI status } \\
\text { Stage II } \\
\text { Stage III endometrioid, no } \\
\text { residual disease } \\
\text { Non-endometrioid }\end{array}$ \\
\hline MRC ASTEC ${ }^{10}$ & & $\begin{array}{l}\text { No papillary serous and CC } \\
\text { - Stages IA-IB, G3 } \\
\text { - Stages IC-IIA, GI-2 }\end{array}$ & & $\begin{array}{l}\text { Papillary serous and CC } \\
\text { subtypes } \\
\text { All other subtypes } \\
\text { - IC, G3 } \\
\text { - IIA, G3 } \\
\text { - IIB }\end{array}$ \\
\hline ASTRO/ASCO 35 & & & $\begin{array}{l}\text { G3 } \\
\geq 50 \% \mathrm{MI}\end{array}$ & \\
\hline
\end{tabular}

Notes: *PRF (pathological risk factors): grade 2 or 3, positive LVSI, myometrial invasion to outer third. Not all of the trials provided information for each risk group. Abbreviations: G, grade; MI, myometrial invasion; EC, endometrial carcinoma; CC, clear cell; PRF, pathological risk factors; LVSI, lymphovascular space invasion; ASTRO, American Society for Radiation Oncology; ASCO, American Society of Clinical Oncology. 
Table 2 Randomized trials of adjuvant radiation and clinical results

\begin{tabular}{|c|c|c|c|}
\hline Reference & Arm & Locoregional relapse & Overall survival \\
\hline \multirow[t]{2}{*}{ Aalders et $\mathrm{a}^{52}$} & $\operatorname{VCB}(n=277)$ & $7 \% 5$ years & $89 \% 5$ years \\
\hline & $\mathrm{EBRT}+\mathrm{VCB}(\mathrm{n}=263)$ & $2 \% 5$ years & $91 \% 5$ years \\
\hline \multirow[t]{2}{*}{ PORTEC-I ${ }^{37}$} & Observation $(n=360)$ & $14 \% 5$ years & $85 \% 5$ years \\
\hline & $\operatorname{EBRT}(n=354)$ & $4 \% 5$ years & $81 \% 5$ years \\
\hline \multirow[t]{2}{*}{ GOG-9938 } & Observation $(n=202)$ & $12 \% 2$ years & $86 \% 4$ years \\
\hline & $\operatorname{EBRT}(n=190)$ & $3 \% 2$ years & $92 \% 4$ years \\
\hline \multirow[t]{2}{*}{ ASTEC/EN. $5^{10}$} & Observation $(n=453)$ & $7 \% 5$ years & $83.9 \% 5$ years \\
\hline & $\operatorname{EBRT}(n=452)$ & $4 \% 5$ years & $83.5 \% 5$ years \\
\hline \multirow[t]{2}{*}{ PORTEC-2 ${ }^{44}$} & $\operatorname{EBRT}(n=2 \mid 4)$ & $2 \% 5$ years & $80 \% 5$ years \\
\hline & $\operatorname{VCB}(n=213)$ & $2 \% 5$ years & $85 \% 5$ years \\
\hline \multirow[t]{2}{*}{ Sorbe et $\mathrm{al}^{40}$} & $E B R T+V C B(n=264)$ & $1.5 \% 5$ years & $89 \% 5$ years \\
\hline & $\operatorname{VCB}(n=263)$ & $5 \% 5$ years & $90 \% 5$ years \\
\hline
\end{tabular}

Abbreviations: VCB, vaginal cuff brachytherapy; EBRT, external beam radiotherapy.

Table 3 Adjuvant treatment according to the NCCN guidelines (v.l.2017)

\begin{tabular}{|c|c|c|c|c|}
\hline \multirow[t]{2}{*}{ Stage } & \multirow{2}{*}{$\begin{array}{l}\text { Postoperative } \\
\text { findings }\end{array}$} & \multicolumn{3}{|c|}{ Tumor grade } \\
\hline & & GI & G2 & G3 \\
\hline \multirow[t]{5}{*}{ I } & $\begin{array}{l}<50 \% \text { MI, risk } \\
\text { factors (-) }\end{array}$ & Observe & $\begin{array}{l}\text { Observe } \\
\text { VCB }\end{array}$ & $\begin{array}{l}\text { Observe } \\
\text { VCB }\end{array}$ \\
\hline & $<50 \%$, risk & Observe & Observe & Observe \\
\hline & factors $(+)$ & VCB & $\begin{array}{l}\text { VCB } \pm \text { EBRT } \\
\text { EBRT }\end{array}$ & $\begin{array}{l}\text { VCB } \pm \text { EBRT } \\
\text { EBRT }\end{array}$ \\
\hline & $\begin{array}{l}\geq 50 \% \text { MI, risk } \\
\text { factors (-) }\end{array}$ & $\begin{array}{l}\text { Observe } \\
\text { VCB }\end{array}$ & $\begin{array}{l}\text { Observe } \\
\text { VCB }\end{array}$ & $\begin{array}{l}\text { VCB } \pm \text { EBRT } \\
\text { EBRT } \\
\text { Observe }\end{array}$ \\
\hline & $\begin{array}{l}\geq 50 \% \text { MI, risk } \\
\text { factors }(+)\end{array}$ & $\begin{array}{l}\text { Observe } \\
\text { VCB } \pm \text { EBRT } \\
\text { EBRT }\end{array}$ & $\begin{array}{l}\text { Observe } \\
\text { VCB } \pm \text { EBRT } \\
\text { EBRT }\end{array}$ & $\begin{array}{l}\text { EBRT } \pm \text { VCB } \\
\pm \text { systemic } \\
\text { therapy } \\
\text { VCB } \pm \text { systemic } \\
\text { therapy }\end{array}$ \\
\hline II & & $\begin{array}{l}\text { VCB } \pm E B R T \\
\text { EBRT }\end{array}$ & $\begin{array}{l}\text { VCB } \pm E B R T \\
E B R T\end{array}$ & $\begin{array}{l}\text { EBRT } \pm \text { VCB } \\
\pm \text { systemic } \\
\text { therapy }\end{array}$ \\
\hline
\end{tabular}

Note: Risk factors: age, positive lymphovascular invasion, tumor size, depth of invasion and lower uterine involvement.

Abbreviations: NCCN, National Comprehensive Cancer Network; G, grade; MI, myometrial invasion; VCB, vaginal cuff brachytherapy; EBRT, external beam radiotherapy.

postoperative irradiation among intermediate- and high-risk patients. ${ }^{22}$ Discrepancies between randomized and database studies are due to including low-risk patients who die from $\mathrm{EC}$ and due to a lack of power in the randomized trials. It has been calculated that 2115 patients in each arm are necessary to carry out a powered enough assay. ${ }^{21}$

\section{VCB as a boost}

No randomized trial has evaluated the value of VCB boost after EBRT, but two studies have evaluated the effect of EBRT added to VCB. ${ }^{40,45}$ While the older study ${ }^{45}$ did not find any statistically significant difference by adding EBRT, after a median of 20.5 years of follow-up, Sorbe et a ${ }^{40}$ observed a significant improvement in the locoregional relapses (Table 2), although no differences in survival were achieved. A SEER database analysis demonstrated a significant survival advantage among 1333 early stage uterine papillary serous (UPSC) and CC carcinoma patients who had undergone adjuvant radiotherapy (106 vs. 151 months for observation and radiotherapy, respectively $[p=0.006]) .{ }^{46}$ Nevertheless, a later analysis of 1653 patients who had high-risk stages I-II, high-grade endometrioid carcinoma and non-endometrioid histologies was unable to find any improvement in cancer survival by adding VCB after EBRT. ${ }^{47}$ Similar results were found after an analysis of 3395 high-risk stages I and II EC patients retrieved from the same database. ${ }^{48}$ Lack of patient selection and control of confounding variables, such as pathological factors or chemotherapy among patients at a high risk of distant relapses, might explain it because the SEER database does not record specific pathological information, site of relapse or chemotherapy administration. Bingham et $a l^{43}$ who analyzed stage III EC reported an improvement in survival only with the addition of VCB to EBRT among the subgroup with cervical involvement. In a multivariate Cox analysis, chemotherapy has been shown to reduce the crude percentage of initial extra-abdominal failure from $19 \%$ to $10 \%{ }^{49}$ compared with whole-abdominal irradiation and improve survival significantly. ${ }^{43} \mathrm{An}$ increase in late toxicity linked to the use of VCB as a boost has been described. Despite these facts, $28 \%$ of the respondents of a recent survey stated to use this approach only in a highrisk disease, and $6.3 \%$ of the respondents always use it. ${ }^{50}$

\section{High-risk and unfavorable histology tumors}

This group of patients include those with high-risk endometrioid carcinomas (grade 3 and locally advanced tumors) and 
high-risk histologies (UPSC and CC tumors). Stages III-IV of UPSC and CC tumors have a more aggressive natural history and lower overall survival than grade 3 endometrioid carcinomas $\left(55 \%, 68 \%\right.$ and $77 \%$, respectively). ${ }^{51}$ Patients at stage IC G3 recruited in the Norwegian trial ${ }^{52}$ had lower survival rates than lower risk patients. A retrospective analysis of 125 patients treated for stage IA unfavorable histology endometrial carcinoma indicated an improved 5-year locoregional control and overall survival with postoperative irradiation compared with no irradiation $(97.8 \%$ vs $80.1 \%$, $p=0.018$, and $84.9 \%$ vs $68.1 \%, p=0.0062$, respectively).$^{53}$ The GOG-122 trial demonstrated, in spite of the reduction in local relapses, a detrimental effect in 5-year survival with postoperative radiotherapy (abdominal irradiation [30 Gy] followed by an external pelvic boost up to $45 \mathrm{~Gy}$ ) compared with the group treated with chemotherapy (38\% vs $50 \%$, respectively). ${ }^{49}$ Two other trials ${ }^{54,55}$ included 385 and 345 patients, respectively, and were unable to demonstrate differences between the radiotherapy arm and chemotherapy arm.

A retrospective analysis of 37 patients treated with postoperative VCB without EBRT for early-stage UPSC and $\mathrm{CC}$ was carried out at the Dana-Farber Cancer Institute. Only four patients relapsed; the 2-year vaginal control rate and 2-year disease-free and overall survival were $96.8 \%$, $89.3 \%$ and $100 \%$, respectively. ${ }^{56} \mathrm{~A}$ retrospective analysis of 84 women with stage I UPSC or CC compared postoperative EBRT + VCB with VCB alone. No significant differences were observed in disease-free survival or in overall survival ( $88 \%$ vs $84 \%, p=0.6$, and $100 \%$ vs $94 \%, p=0.6$, respectively).$^{57} \mathrm{~A}$ SEER database analysis found a median survival improvement with the use of postoperative irradiation (106 vs 151 months, $p=0.006) .{ }^{46}$ The analysis of 1653 patients with UPSC, CC and high-grade endometrioid carcinoma, from the same database, found no statistically significant causespecific survival differences between patients treated with postoperative EBRT and EBRT + VCB (85.3\% vs 86.5\%, $p$ $=0.72) .{ }^{47}$ No comparisons with a large number of patients treated with VCB alone have been reported.

\section{Dose fractionation}

The widespread use of HDR brachytherapy has allowed for a greater flexibility in the irradiation delivery. The 2014 American Brachytherapy Society (ABS) update survey ${ }^{34}$ reports that $7 \mathrm{~Gy}$ for three fractions is the most common schedule for postoperative VCB alone and 5 Gy for three fractions is the most common schedule for $\mathrm{VCB}$ as a boost after EBRT, both delivered to a depth of $0.5 \mathrm{~cm}$. Nevertheless, a wide variation in the dose schedules was noted; 24 regimens for monotherapy and 22 as a boost were recorded. Because comparative studies of dose fractionation are scarce, ${ }^{59,60}$ the schedule used depends on the doctors' experience, preference or workload. No clear optimal dose for VCB has been established; the reported doses for $\mathrm{VCB}$ alone range from 35 to 48 Gy EQD2 and 57 to 69 Gy EQD2 after EBRT. ${ }^{39}$ Sorbe et $\mathrm{al}^{59}$ randomized 290 low-risk EC patients to six fractions of $2.5 \mathrm{~Gy}$ (total dose of $15.0 \mathrm{~Gy}$ ) or 5.0 Gy (total dose of 30.0 Gy). No differences on locoregional control were observed, but mucosal atrophy, bleeding and vaginal shortening were significantly more frequent in the 5.0-Gy group. Rovirosa et a ${ }^{60}$ compared two VCB schedules in 319 patients (three fractions after EBRT and six fractions in the exclusive VCB at a dose of 4-6 Gy/fraction, three to four fractions per week vs two fractions after EBRT and four fractions in the exclusive VCB at a dose per fraction of 5-6 Gy daily). No differences in relapses or toxicity were observed. Large doses per fraction have been related to vaginal shortening; 59 2.5 Gy per fraction did not produce a statistically significant vaginal shortening $(0.3 \mathrm{~cm}, 3 \%)$ compared with the pre-VCB measure, while 5 Gy per fraction produced a significant mean vaginal shortening $(2.1 \mathrm{~cm}, 25 \%)$. The percentage of late vagina complications can vary widely depending on the treatment schedule, the length of treated vagina and the score system used for their recording. Owing to the low toxicity associated with the procedure, assays have been carried out to minimize the number of fractions or to reduce the total length of its administration. ${ }^{60-62}$ No significant differences in late toxicity or VC relapses were observed with the accelerated schedules.

\section{Applicator type and position, patient position and volume to treat}

The majority of the treatments are carried out with a singlechannel cylinder $(83.2 \%)$ due to its simplicity and resources compared to the use of colpostats or vaginal molds. ${ }^{63}$ However, this technique is not without its drawbacks. In spite of using the largest cylinder that can comfortably fit into the vagina, there can still be air gaps on the vaginal surface. ${ }^{64}$ This can increase when the vaginal introitus is smaller than the apex. Avoiding the smaller cylinder diameters reduces toxicity. A multichannel cylinder allows a better conformal dosimetry and reduces bladder and rectum doses. ${ }^{65}$ Compared to cylinders, vaginal colpostats can reduce percentage depth doses in the anterior/posterior and lateral directions as well as the dose falloff along the longitudinal axis. ${ }^{66}$ The main drawback is the possibility of producing cold spots due to the vaginal packing. Ring applicators have also been used, 
with similar clinical results to cylinders. ${ }^{67}$ The 5 -year overall survival of 100 patients was $84 \%$, and $6 \%$ of the patients showed failure (one isolate in the vaginal vault and two in the vaginal vault and pelvis simultaneously; three other patients relapsed out of the field or distant). "Dog-ear" vaginal vaults can be underdosed with standard cylinders and are best irradiated with vaginal molds ${ }^{68}$ or ovoids. ${ }^{69}$ Molds do not need vaginal packaging compared with ovoids and provide a good solution in irregular vaults where a good contact between cylinders and mucosa may not be achievable. The classic technique is to create it from a vaginal impression, which can optimize catheter configuration with the aid of computed tomography (CT) imaging ${ }^{70}$ The growing use of the threedimensional (3D) printing technologies in the brachytherapy field ${ }^{71}$ improves mold design and creates highly personalized applicators. These $3 \mathrm{D}$ printing applicators made from $3 \mathrm{D}$ images might improve dose deposition by conforming to the patient's anatomy and optimizing the range of catheter sources to the individual anatomy. ${ }^{72}$ Intravaginal balloons have also been used for postoperative VCB. ${ }^{73}$

Humphrey et $\mathrm{al}^{74}$ assessed $103 \mathrm{CT}$ scans, and air gaps were visible in 38 patients accounting for a total of 67 air gaps. However, air gaps of $>2 \mathrm{~mm}$ that lead to repositioning or use of large cylinders were only reported in 11 out of 103 patients. After correction, only $7 \%$ of the patients had air gaps of $>2 \mathrm{~mm}$. Two other reports have reported $32 \%$ and $72 \%$ of air gaps of $>2 \mathrm{~mm}$, respectively, ${ }^{64,75}$ but the majority are not clinically significant ${ }^{64}$ and only represent $0.86 \%$ of the vaginal surface. The ratio of patients to air pockets has been as high as $58 \%(29 / 50)$ of the patients or $33 \%(45 / 135)$ of the VCB plans. ${ }^{76}$ Their volume can reach up to $2.1 \mathrm{~cm}^{3}$, and the displacement of the vaginal mucosa from the cylinder surface can be up to $1.09 \mathrm{~cm}$. The relationship between the cylinder applicator diameter and air gaps forces the selection of the largest applicator diameter that will comfortably fit into the vagina. Similarly, Onal et $\mathrm{al}^{77}$ described air pockets in $43 \%$ of patients treated with cylinders, but only $6.3 \%$ of the total patients received less than the prescribed dose (average $93.9 \%$ of the prescribed dose, range 79\%-99.2\%). Monte Carlo calculations show a maximum dose deviation due to air pockets of $2.4 \%$ compared with the TG-43 formalism. ${ }^{78}$ This study observed that the most common radial size was between 2 and $3 \mathrm{~mm}$, and the average dose reduction was $14.8 \%$.

Only one study has analyzed the influence of patient position on dose to organs at risk. ${ }^{30}$ Planning with legs extended produced significantly lower rectum $\mathrm{D}_{1 \mathrm{cc}}$ and $\mathrm{D}_{2 \mathrm{cc}}$ values compared with planning in the gynecology position (4.69 vs 5.66 Gy and 4.24 vs 5.14 Gy, respectively). The angle of the applicator influences the location of dose deposition. The "natural" angle position of the cylinder, ${ }^{31}$ which tips the cylinder points posteriorly, has been linked to an increase in the rectal dose, while cylinders placed horizontally reduced rectal doses and increased the bladder values. ${ }^{32}$ Nevertheless, one study failed to demonstrate a correlation between the cylinder angle and the bladder dose although a posterior angle increased rectal $\mathrm{D}_{2 \mathrm{cc}}{ }^{79}$

The majority of the patients have irradiation of the upper $2.5-3 \mathrm{~cm}$ or the upper third of the vagina. Nevertheless, an interesting study limiting the vaginal coverage to the upper $1 \mathrm{~cm}$ length has been reported, but only in the abstract form. ${ }^{80}$ Increasing the length of the vagina irradiation has been linked to an increase in toxicity, ${ }^{81}$ but no relationship has been described between the length of the vagina irradiation and vaginal relapses or survival. ${ }^{82}$

\section{Rectum volume}

Nonsignificant rectal $\mathrm{D}_{2 \mathrm{cc}}$ differences among planned and delivered brachytherapy fractions (14.25 vs $13.95 \mathrm{~Gy}, p$ $=0.155$ ) were observed in a recent study. ${ }^{79}$ In that study, a nonsignificant decrease in rectal volumes on the delivered CTs was observed compared to the planning CT. A positive correlation has been demonstrated between rectal volume and $\mathrm{D}_{\max }, \mathrm{D}_{0.1 \mathrm{cc}}, \mathrm{D}_{1 \mathrm{cc}}$ and $\mathrm{D}_{2 \mathrm{cc}}$, which remained significant in multiple linear regression models. ${ }^{32}$ Rectal contrast, traditionally, has been used to improve rectal visualization in orthogonal radiographs, although it must be avoided because a CT-based study demonstrated a statistically significant increase of up to $10.4 \%$ in some rectal dose parameters. ${ }^{83}$ This was linked to an increase in the rectal volume of up to $27.6 \pm 41.6 \mathrm{~cm}^{3}$. The presence of gas pockets in the rectum during VCB has also been associated with higher rectal doses. ${ }^{84}$ Removal of these pockets significantly decreased the mean rectum volume by $29 \%$ and $\mathrm{D}_{2 \mathrm{cc}}$ by $11 \%$ as well as the rectum dose area under the curve by $33 \%$. In light of these data, a prospective trial was carried out to analyze the effect of rectal enemas on rectal dosimetric parameters. ${ }^{85,86}$ The enema protocol involved two Fleet enemas, the first administered the night before the procedure and the second before hospital admittance for the procedure. No significant dose parameter differences were observed between fractions with or without Fleet enemas.

\section{Bladder volume}

Patel et al $^{79}$ observed lower bladder volumes on planning CT compared with the treatment $\mathrm{CT}$ acquired before each brachytherapy fraction. At the same time, the delivered bladder 
$\mathrm{D}_{2 \mathrm{cc}}$ was significantly higher than the planned $\mathrm{D}_{2 \mathrm{cc}}(18.83$ vs $13.2 \mathrm{~Gy}, p=0.0053)$. Studies comparing full and empty bladders have been reported. A total of 15 patients underwent a CT scan before the first fraction with an empty bladder followed by a second CT scan done with the bladder full. ${ }^{87}$ This maneuver increased significantly the cylinder-to-bowel distance (1.68 vs $1.2 \mathrm{~cm}, p=0.006)$. The full bladder produced a significant $18.7 \%$ bladder $\mathrm{D}_{2 \mathrm{cc}}$ increase and a nonsignificant rectum $\mathrm{D}_{2 \mathrm{cc}}$ increase of $0.5 \%$. A nonsignificant reduction in sigmoid (-15.1\%) and bowel $(-10.5 \%) \mathrm{D}_{2 \mathrm{cc}}$ was observed. Another study reported a reduction of $0.5 \mathrm{~Gy}$ on average in bladder doses in 35 out of 45 women with an empty bladder, but 10 out of 45 patients' bladder doses increased to $0.2 \mathrm{~Gy}$ on average ${ }^{88} \mathrm{D}_{2 \mathrm{cc}}$ significantly decreased the bladder empty (4.9 vs $4.6 \mathrm{~Gy}$ ), while $\mathrm{V}_{50}$ increased significantly ( $10.1 \%$ vs $17.7 \%$ ). It was associated with a significant $\mathrm{D}_{2 \mathrm{cc}}$ bowel dose reduction (4.1 vs 4.6 Gy). Hoskin and Vidler ${ }^{89}$ carried out a comparative paired analysis with an empty bladder and three full bladder volumes (35, 70 and $100 \mathrm{~mL}$ ). Mean maximum bladder dose was lower with the empty bladder than with any of the full ones. Stewart et $\mathrm{a}^{90}$ compared CT-planning dose parameters on fractions with an empty bladder and fractions with a full bladder with images acquired 1 hour after consumption of $32 \mathrm{oz}$ of water. $\mathrm{D}_{2 \mathrm{cc}}$ and $\mathrm{V}_{50}$ were significantly greater in the full bladder state ( $4.56 \mathrm{vs} 4.06 \mathrm{~Gy}$ and $18.47 \mathrm{vs}$ $10.52 \mathrm{~cm}^{3}$, respectively). The median distance to the nearest point of bowel nearly doubled with the filling of the bladder (11.6 vs $5.75 \mathrm{~mm}, p=0.002$ ). The instillation of $180 \mathrm{~mL}$ to an empty bladder produced significant $\mathrm{D}_{50 \%}$ bladder and bowel dose reduction of $36.7 \%$ and $21.4 \%$, respectively. ${ }^{33} \mathrm{~A}$ significant $39.7 \% \mathrm{D}_{2 \mathrm{cc}}$ reduction in the bowel values was also seen.

\section{Dose prescription}

Until recently, two-dimensional (2D) dosimetry calculated from orthogonal RX films was the standard. The spread of CT images raised the need to evaluate the impact of 3D images on dosimetry. Studies have demonstrated the variation of doses to organs depending on the calculation method. Comparisons of International Commission of Radiation Units and Measurements (ICRU) doses on 2D images and maximum and $\mathrm{D}_{2 \mathrm{cc}}$ doses on 3D images were carried out. ${ }^{91}$ Maximum bladder and rectal doses were $178 \%$ and $135 \%$ of ICRU doses, respectively. No significant bladder dose differences between $\mathrm{D}_{2 \mathrm{cc}}$ and ICRU doses were observed, but a significant rectal difference was found, with a ratio of $\mathrm{D}_{2 \mathrm{cc}}$ to ICRU equal to 0.87 . Bladder and rectal $\mathrm{D}_{2 \mathrm{cc}}$ values were $59 \%$ and $64 \%$ of maximum doses, respectively. Kim et al ${ }^{92}$ described significant lower $\mathrm{D}_{2 \mathrm{cc}}$ rectum ( $82.6 \%$ vs $78.2 \%$ ) and bladder
( $80.6 \%$ vs $77 \%$ ) doses with $3 \mathrm{D}$ planning compared with $2 \mathrm{D}$ planning. Hung et $\mathrm{al}^{33}$ reported small but significant lower $\mathrm{D}_{2 \mathrm{cc}}$ doses than the respective ICRU values.

Usually, dose is prescribed to the applicator surface or at $0.5 \mathrm{~cm}$ depth. The rationale is the vaginal wall thickness and the depth placement of the lymphatic vessels. In all, 50\% of the lymphatic channels are located at $1 \mathrm{~mm}$ beneath the mucosa and $7 \%$ lie within $3-4 \mathrm{~mm} .{ }^{93} \mathrm{~A}$ total of $95 \%$ of vaginal lymphatic channels are located within the first $3 \mathrm{~mm}$ from the vaginal surface. The need to individualize the prescription depth according to the vaginal thickness has been suggested in order to reduce toxicity. Surface dose prescription produces a more uniform dose to the mucosa and at every depth, an acceptable target coverage and almost the same dose falloff compared with $0.5 \mathrm{~cm}$ depth dose prescription. ${ }^{94}$ Dose surface ranged from $81 \%$ to $172 \%$ for the 0.5 -cm depth prescription compared with $90 \%$ to $106 \%$ for the surface prescription, and large dose variations at the surface appeared with the $2-\mathrm{cm}$ cylinder. A formula was derived to transform $0.5-\mathrm{cm}$ depth dose prescription to surface prescription by magnifying the prescription dose by an $M$ factor that takes into account the cylinder size $(S)$ and activated length $(L): M \approx 1.00+0.64(\mathrm{~cm}) / L+1.23(\mathrm{~cm}) / S$. That study also reported extreme cold and hot spots when no optimization points were used at the cylinder tip.

\section{Custom or standard radiotherapy planning}

Nowadays, the majority of VCB treatments are 3D planned (83.2\%) according to the 2014 ABS survey, but the majority of the respondents (73.4\%) only planned the first fraction. ${ }^{63}$ ABS guidelines do not demand that each fraction of VCB is planned because there is an assumed fixed geometry of the implant. Image at each fraction of three increments costs $35 \%$ compared with a single simulation but did not produce any dosimetric advantage. ${ }^{95}$ Similar results with single-channel or multichannel cylinders were observed; imaging at each fraction was $19 \%$ and $22 \%$ more expensive, respectively ${ }^{96}$ Sabater et a ${ }^{97}$ compared three approaches for dose summation, a single plan approach that used a crude dose summation of a single plan that was replicated to every fraction and dose summation of customized plans for every fraction using both rigid and deformable registration. No significant rectal dose differences were observed, but some limited differences in bladder dose metrics were found, something which does not justify the higher costs linked to the customized approach. Multichannel cylinders have also been evaluated in this setting, ${ }^{98}$ and results show an excess of maximum bladder or rectum doses in $41 \%$ of cases when a single plan approach was used. 


\section{Image-guided brachytherapy}

Nowadays, simulation for postoperative EC relies on CT volumetric images, which have proven to detect air pockets around the cylinders ${ }^{74,76,77}$ or inside the rectum ${ }^{84}$ or evaluate bladder volume ${ }^{79}$ and improve dose deposition. Magnetic resonance imaging (MRI) is considered the optimal imaging method to delineate volumes in cervical cancer, ${ }^{99}$ but its value in EC is less clear and availability is limited, so strategies to integrate clinical images into the radiotherapy workflow have been studied. ${ }^{100}$ Average absolute percentage dose differences for the bladder, rectum and prescription points on CT and MRI were $2.2 \%, 2.3 \%$ and $2.2 \%$, respectively, and the mean central source deviation was $0.6 \mathrm{~mm}$, which was associated with longer acquisition times in MRI. ${ }^{101}$ Chapman et al ${ }^{102}$ carried out sequential MRI and CT scans. They observed using MRI that $69 \%$ of the patients had at least $1 \mathrm{~cm}^{3}$ of VC receiving $<75 \%$ of the prescription dose. The reasons were that areas of undistended vagina now seen in CT and suture material prevented full cylinder insertion. These results question the minimum doses necessary to avoid relapses. Owing to the steep dose gradient, small changes in the structures close to the sources produce large dose-volume histogram changes. Applicator displacement between fractions has a similar effect, so reproducibility is crucial. Although the ABS guidelines recommend a customized plan with each fraction, they state that this may not be necessary, assuming a fixed geometry of the implant for every insertion based on the first fraction. ${ }^{103}$

\section{Comparison of brachytherapy with advanced EBRT techniques (intensity- modulated radiotherapy-stereotactic body radiotherapy)}

Brachytherapy has intrinsic advantages compared to modern EBRT techniques, mainly intensity-modulated radiotherapy (IMRT) and stereotactic body radiotherapy (SBRT), due to the close contact between radioactive sources and volume to treat. IMRT has generally been used to irradiate the pelvis but with less toxicity. ${ }^{104}$ The main drawback to the use of EBRT techniques is that the vagina moves, so there is a risk of geographical "miss of target", which leads to increased margins and higher integral doses to small bowel. ${ }^{105}$ Average $\mathrm{VC}$ movement for 11 patients was $16.2 \pm 8.3 \mathrm{~mm}$ during an EBRT course, with a maximum movement of $34.5 \mathrm{~mm} .{ }^{106}$ Large variations in bladder and rectum volumes correlate with significant displacement of the VC. ${ }^{107}$ Aydogan et $\mathrm{al}^{108}$ concluded that IMRT could be an alternative to HDR brachytherapy and provided a suitable immobilization system. Both techniques, brachytherapy and IMRT, covered the target volume well, but brachytherapy produced higher doses. In order to control vaginal movements an applicator-guided IMRT technique has been proposed. ${ }^{109} \mathrm{It}$ was used to compare 3D conformal radiotherapy (3D-CRT), IMRT and volumetric-modulated arc therapy (VMAT) in irradiating the VC. ${ }^{110}$ Dose coverage was similar across the three techniques. VMAT showed the highest level of conformity and produced a significant reduction in rectal and bladder volumes compared with 3D-CRT. VMAT needed $28 \%$ less monitor units compared with IMRT, and treatment duration reduced from 11 to $<3$ minutes for a dose of 6 Gy. Pedicini et al ${ }^{111,112}$ compared VMAT, IMRT and 3D-CRT using a vaginal cylinder for vaginal immobilization to $3 \mathrm{D}$ brachytherapy. The cylinder was able to reduce the movement in the VMAT course and reduced planning target volume margin to $2 \mathrm{~mm}$. EBRT techniques always delivered higher integral doses but reduced rectal doses compared with brachytherapy. VMAT produced a uniform dose distribution, while VCB doses were much higher than the prescription. No direct cost comparisons between these modalities have been published, but three fractions of VCB course with one image study has been calculated to cost between US $\$ 1235$ and $\$ 1293,{ }^{95}$ while four to five fractions of SBRT for lung cancer cost $\$ 10616 .{ }^{113}$

In summary, we believe that despite the widespread use of the VCB and the simplicity of its performance, several technical subjects have to be considered by the radiation oncologists aside from the usual groups of risk involved in patient selection. The technical subjects reported so far have been reviewed here, although additional research is merited, such as the impact of VCB on survival, dose-fractionation direct comparisons or the use of short schedules.

\section{Acknowledgment}

The authors would like to thank Phil Hoddy for language editing.

\section{Disclosure}

The authors report no conflicts of interest in this work.

\section{References}

1. Bray F, Loos AH, Oostindier M, Weiderpass E. Geographic and temporal variations in cancer of the corpus uteri: incidence and mortality in pre- and postmenopausal women in Europe. Int J Cancer. 2005;117(1): 123-131. 
2. Ferlay J, Soerjomataram I, Dikshit R, et al. Cancer incidence and mortality worldwide: sources, methods and major patterns in GLOBOCAN 2012. Int J Cancer. 2015;136(5):E359-E386.

3. Creutzberg CL, Nout RA. The role of radiotherapy in endometrial cancer: current evidence and trends. Curr Oncol Rep. 2011;13(6): 472-478.

4. Ishiyama H, Satoh T, Sekiguchi A, et al. Comparison of three different techniques of low-dose-rate seed implantation for prostate cancer. $J$ Contemp Brachytherapy. 2015;7(1):3-9.

5. Hasan S, Francis A, Hagenauer A, et al. The role of brachytherapy in organ preservation for penile cancer: a meta-analysis and review of the literature. Brachytherapy. 2015;14(4):517-524.

6. Arenas M, Arguis M, Diez-Presa L, et al. Hypofractionated highdose-rate plesiotherapy in nonmelanoma skin cancer treatment Brachytherapy. 2015;14(6):859-865.

7. Takacsi-Nagy Z, Martinez-Mongue R, Mazeron JJ, Anker CJ, Harrison LB. American Brachytherapy Society Task Group Report: combined external beam irradiation and interstitial brachytherapy for base of tongue tumors and other head and neck sites in the era of new technologies. Brachytherapy. 2017;16(1):44-58.

8. Arenas M, Gascon M, Rovirosa A, et al. The effect of lymphadenectomy and radiotherapy on recurrence and survival in endometrial carcinoma. Experience in a population reference centre. Rep Pract Oncol Radiother. 2015;20(1):50-56.

9. Kilgore LC, Partridge EE, Alvarez RD, et al. Adenocarcinoma of the endometrium: survival comparisons of patients with and without pelvic node sampling. Gynecol Oncol. 1995;56(1):29-33.

10. ASTEC Study Group, Kitchener H, Swart AM, Qian Q, Amos C, Parmar MK. Efficacy of systematic pelvic lymphadenectomy in endometrial cancer (MRC ASTEC trial): a randomised study. Lancet. 2009;373(9658):125-136.

11. Benedetti Panici P, Basile S, Maneschi F, et al. Systematic pelvic lymphadenectomy vs. no lymphadenectomy in early-stage endometrial carcinoma: randomized clinical trial. J Natl Cancer Inst 2008;100(23):1707-1716.

12. Mariani A, Dowdy SC, Cliby WA, et al. Prospective assessment of lymphatic dissemination in endometrial cancer: a paradigm shift in surgical staging. Gynecol Oncol. 2008;109(1):11-18.

13. Papadia A, Remorgida V, Salom EM, Ragni N. Laparoscopic pelvic and paraaortic lymphadenectomy in gynecologic oncology. J Am Assoc Gynecol Laparosc. 2004;11(3):297-306.

14. Walker JL, Piedmonte MR, Spirtos NM, et al. Laparoscopy compared with laparotomy for comprehensive surgical staging of uterine cancer: Gynecologic Oncology Group Study LAP2. J Clin Oncol. 2009;27(32):5331-5336.

15. Papadia A, Imboden S, Siegenthaler F, et al. Laparoscopic indocyanine green sentinel lymph node mapping in endometrial cancer. Ann Surg Oncol. 2016;23(7):2206-2211.

16. Huang HJ, Tang YH, Chou HH, et al. Treatment failure in endometrial carcinoma. Int J Gynecol Cancer. 2014;24(5):885-893.

17. Mariani A, Webb MJ, Keeney GL, Lesnick TG, Podratz KC. Surgical stage I endometrial cancer: predictors of distant failure and death. Gynecol Oncol. 2002;87(3):274-280.

18. Blecharz P, Urbanski K, Mucha-Malecka A, et al. Hematogenous metastases in patients with stage I or II endometrial carcinoma. Strahlenther Onkol. 2011;187(12):806-811.

19. Murphy KT, Rotmensch J, Yamada SD, Mundt AJ. Outcome and patterns of failure in pathologic stages I-IV clear-cell carcinoma of the endometrium: implications for adjuvant radiation therapy. Int J Radiat Oncol Biol Phys. 2003;55(5):1272-1276.

20. Barlin JN, Wysham WZ, Ferda AM, et al. Location of disease in patients who die from endometrial cancer: a study of 414 patients from a single institution. Int J Gynecol Cancer. 2012;22(9):1527-1531.

21. Harkenrider MM, Adams W, Block AM, Kliethermes S, Small W Jr, Grover S. Improved overall survival with adjuvant radiotherapy for high-intermediate and high risk stage I endometrial cancer. Radiother Oncol. 2017;122(3):452-457.
22. Chino JP, Jones E, BerchuckA, Secord AA, Havrilesky LJ. The influence of radiation modality and lymph node dissection on survival in earlystage endometrial cancer. Int J Radiat Oncol Biol Phys. 2012;82(5): 1872-1879.

23. Lee CM, Szabo A, Shrieve DC, Macdonald OK, Gaffney DK. Frequency and effect of adjuvant radiation therapy among women with stage I endometrial adenocarcinoma. JAMA. 2006;295(4):389-397.

24. Mell LK, Carmona R, Gulaya S, et al. Cause-specific effects of radiotherapy and lymphadenectomy in stage I-II endometrial cancer: a population-based study. J Natl Cancer Inst. 2013;105(21):1656-1666.

25. Bertelsen K, Ortoft G, Hansen ES. Survival of Danish patients with endometrial cancer in the intermediate-risk group not given postoperative radiotherapy: the Danish Endometrial Cancer Study (DEMCA). Int J Gynecol Cancer. 2011;21(7):1191-1199.

26. Fanning J, Hoffman ML, Andrews SJ, Harrah AW, Feldmeier JJ. Costeffectiveness analysis of the treatment for intermediate risk endometrial cancer: postoperative brachytherapy vs. observation. Gynecol Oncol. 2004;93(3):632-636.

27. Patel MK, Cote ML, Ali-Fehmi R, Buekers T, Munkarah AR, Elshaikh MA. Trends in the utilization of adjuvant vaginal cuff brachytherapy and/or external beam radiation treatment in stage I and II endometrial cancer: a surveillance, epidemiology, and end-results study. Int J Radiat Oncol Biol Phys. 2012;83(1):178-184.

28. Arenas M, Sabater S, Gascon M, et al. Quality assurance in radiotherapy: analysis of the causes of not starting or early radiotherapy withdrawal. Radiat Oncol. 2014;9:260.

29. Sabater S, Arenas M, Berenguer R, et al. Body mass index and doses at organs at risk in a Mediterranean population treated with postoperative vaginal cuff brachytherapy. Cancer Res Treat. 2015;47(3):473-479.

30. Iati G, Pontoriero A, Mondello S, et al. Three-dimensional treatment planning for vaginal cuff brachytherapy: dosimetric effects on organs at risk according to patients position. Brachytherapy. 2014;13(6): 568-571.

31. Hoskin PJ, Bownes P, Summers A. The influence of applicator angle on dosimetry in vaginal vault brachytherapy. $\mathrm{Br} J$ Radiol. 2002;75(891):234-237.

32. Sabater S, Arenas M, Berenguer R, et al. Dosimetric analysis of rectal filling on rectal doses during vaginal cuff brachytherapy. Brachytherapy. 2015;14(4):458-463.

33. Hung J, Shen S, De Los Santos JF, Kim RY. Image-based 3D treatment planning for vaginal cylinder brachytherapy: dosimetric effects of bladder filling on organs at risk. Int J Radiat Oncol Biol Phys. 2012;83(3): 980-985.

34. Harkenrider MM, Block AM, Alektiar KM, et al. American Brachytherapy Task Group Report: adjuvant vaginal brachytherapy for earlystage endometrial cancer: a comprehensive review. Brachytherapy. 2017;16(1):95-108.

35. Meyer LA, Bohlke K, Powell MA, et al. Postoperative radiation therapy for endometrial cancer: American Society of Clinical Oncology Clinical Practice Guideline Endorsement of the American Society for Radiation Oncology Evidence-Based Guideline. J Clin Oncol. 2015;33(26):2908-2913.

36. Sorbe B, Nordstrom B, Maenpaa J, et al. Intravaginal brachytherapy in FIGO stage I low-risk endometrial cancer: a controlled randomized study. Int J Gynecol Cancer. 2009;19(5):873-878.

37. Creutzberg CL, van Putten WL, Koper PC, et al. Surgery and postoperative radiotherapy versus surgery alone for patients with stage-1 endometrial carcinoma: multicentre randomised trial. PORTEC Study Group. Post Operative Radiation Therapy in Endometrial Carcinoma. Lancet. 2000;355(9213):1404-1411.

38. Keys HM, Roberts JA, Brunetto VL, et al. A phase III trial of surgery with or without adjunctive external pelvic radiation therapy in intermediate risk endometrial adenocarcinoma: a Gynecologic Oncology Group study. Gynecol Oncol. 2004;92(3):744-751.

39. Kong A, Johnson N, Kitchener HC, Lawrie TA. Adjuvant radiotherapy for stage I endometrial cancer. Cochrane Database Syst Rev. 2012;(4):CD003916. 
40. Sorbe B, Horvath G, Andersson H, Boman K, Lundgren C, Pettersson B. External pelvic and vaginal irradiation versus vaginal irradiation alone as postoperative therapy in medium-risk endometrial carcinoma - a prospective randomized study. Int J Radiat Oncol Biol Phys. 2012;82(3): 1249-1255.

41. Wright JD, Fiorelli J, Kansler AL, et al. Optimizing the management of stage II endometrial cancer: the role of radical hysterectomy and radiation. Am J Obstet Gynecol. 2009;200(4):419.e1-419.e7.

42. Rydzewski NR, Strohl AE, Donnelly ED, et al. Receipt of vaginal brachytherapy is associated with improved survival in women with stage I endometrioid adenocarcinoma of the uterus: a National Cancer Data Base study. Cancer. 2016;122(23):3724-3731.

43. Bingham B, Orton A, Boothe D, et al. Brachytherapy improves survival in stage III endometrial cancer with cervical involvement. Int J Radiat Oncol Biol Phys. 2017;97(5):1040-1050.

44. Nout RA, Smit VT, Putter H, et al. Vaginal brachytherapy versus pelvic external beam radiotherapy for patients with endometrial cancer of high-intermediate risk (PORTEC-2): an open-label, non-inferiority, randomised trial. Lancet. 2010;375(9717):816-823.

45. Onsrud M, Cvancarova M, Hellebust TP, Trope CG, Kristensen GB, Lindemann K. Long-term outcomes after pelvic radiation for earlystage endometrial cancer. J Clin Oncol. 2013;31(31):3951-3956.

46. Kim A, Schreiber D, Rineer J, Choi K, Rotman M. Impact of adjuvant external-beam radiation therapy in early-stage uterine papillary serous and clear cell carcinoma. Int J Radiat Oncol Biol Phys. 2011;81(4):e639-e644.

47. Nagar H, Yan W, Parashar B, et al. Adjuvant pelvic radiation therapy \pm vaginal brachytherapy in patients with high-risk stage I or stage II uterine papillary serous, clear cell, and high-grade endometrioid carcinoma. Am J Clin Oncol. 2016;39(4):335-339.

48. Crosby MA, Tward JD, Szabo A, Lee CM, Gaffney DK. Does brachytherapy improve survival in addition to external beam radiation therapy in patients with high risk stage I and II endometrial carcinoma? Am J Clin Oncol. 2010;33(4):364-369.

49. Randall ME, Filiaci VL, Muss H, et al. Randomized phase III trial of whole-abdominal irradiation versus doxorubicin and cisplatin chemotherapy in advanced endometrial carcinoma: a Gynecologic Oncology Group Study. J Clin Oncol. 2006;24(1):36-44.

50. Small W Jr, Du Bois A, Bhatnagar S, et al. Practice patterns of radiotherapy in endometrial cancer among member groups of the gynecologic cancer intergroup. Int J Gynecol Cancer. 2009;19(3):395-399.

51. Hamilton CA, Cheung MK, Osann K, et al. Uterine papillary serous and clear cell carcinomas predict for poorer survival compared to grade 3 endometrioid corpus cancers. Br J Cancer. 2006;94(5):642-646.

52. Aalders J, Abeler V, Kolstad P, Onsrud M. Postoperative external irradiation and prognostic parameters in stage I endometrial carcinoma: clinical and histopathologic study of 540 patients. Obstet Gynecol. 1980;56(4):419-427.

53. Ly D, Rowley BD, Dodson MK, et al. Adjuvant radiation in early stage, unfavorable histology endometrial carcinoma is associated with improved local control and survival. Gynecol Oncol. 2014;133(2): 250-255.

54. Susumu N, Sagae S, Udagawa Y, et al. Randomized phase III trial of pelvic radiotherapy versus cisplatin-based combined chemotherapy in patients with intermediate- and high-risk endometrial cancer: a Japanese Gynecologic Oncology Group Study. Gynecol Oncol. 2008;108(1):226-233.

55. Maggi R, Lissoni A, Spina F, et al. Adjuvant chemotherapy vs radiotherapy in high-risk endometrial carcinoma: results of a randomised trial. Br J Cancer. 2006;95(3):266-271.

56. Townamchai K, Berkowitz R, Bhagwat M, et al. Vaginal brachytherapy for early stage uterine papillary serous and clear cell endometrial cancer. Gynecol Oncol. 2013;129(1):18-21.

57. Tetreault-Laflamme A, Nguyen-Huynh TV, Carrier JF, et al. Adjuvant chemotherapy and vaginal vault brachytherapy with or without pelvic radiotherapy for stage 1 papillary serous or clear cell endometrial cancer. Int J Gynecol Cancer. 2016;26(2):301-306.
58. Colombo N, Preti E, Landoni F, et al. Endometrial cancer: ESMO Clinical Practice Guidelines for diagnosis, treatment and follow-up. Ann Oncol. 2013;24(Suppl 6):vi33-38.

59. Sorbe B, Straumits A, Karlsson L. Intravaginal high-dose-rate brachytherapy for stage I endometrial cancer: a randomized study of two doseper-fraction levels. Int J Radiat Oncol Biol Phys. 2005;62(5):1385-1389.

60. Rovirosa A, Ascaso C, Arenas M, et al. Can we shorten the overall treatment time in postoperative brachytherapy of endometrial carcinoma? Comparison of two brachytherapy schedules. Radiother Oncol. 2015;116(1):143-148.

61. Rios I, Rovirosa A, Ascaso C, et al. Vaginal-cuff control and toxicity results of a daily HDR brachytherapy schedule in endometrial cancer patients. Clin Transl Oncol. 2016;18(9):925-930.

62. Rovirosa A, Ascaso C, Herreros A, et al. A new short daily brachytherapy schedule in postoperative endometrial carcinoma. Preliminary results. Brachytherapy. 2017;16(1):147-152.

63. Harkenrider MM, Grover S, Erickson BA, et al. Vaginal brachytherapy for postoperative endometrial cancer: 2014 Survey of the American Brachytherapy Society. Brachytherapy. 2016;15(1):23-29.

64. Cameron AL, Cornes P, Al-Booz H. Brachytherapy in endometrial cancer: quantification of air gaps around a vaginal cylinder. Brachytherapy. 2008;7(4):355-358.

65. Demanes DJ, Rege S, Rodriquez RR, Schutz KL, Altieri GA, Wong $\mathrm{T}$. The use and advantages of a multichannel vaginal cylinder in high-dose-rate brachytherapy. Int J Radiat Oncol Biol Phys. 1999;44(1):211-219.

66. Kim RY, Pareek P, Duan J, Murshed H, Brezovich I. Postoperative intravaginal brachytherapy for endometrial cancer; dosimetric analysis of vaginal colpostats and cylinder applicators. Brachytherapy. 2002;1(3):138-144.

67. Vanneste BG, Meijnen P, Hammerstein CS, et al. Postoperative brachytherapy for endometrial cancer using a ring applicator. Brachytherapy. 2015;14(2):273-278.

68. E1 Khoury C, Dumas I, Tailleur A, Morice P, Haie-Meder C. Adjuvant brachytherapy for endometrial cancer: advantages of the vaginal mold technique. Brachytherapy. 2015;14(1):51-55.

69. Tuncel N, Garipagaoglu M, Kizildag AU, Andic F, Toy A. Optimisation techniques in vaginal cuff brachytherapy. $\mathrm{Br} J$ Radiol. 2009;82(983):936-940.

70. Nilsson S, Moutrie Z, Cheuk R, et al. A unique approach to highdose-rate vaginal mold brachytherapy of gynecologic malignancies. Brachytherapy. 2015;14(2):267-272.

71. Arenas M, Sabater S, Sintas A, et al. Individualized 3D scanning and printing for non-melanoma skin cancer brachytherapy: a financial study for its integration into clinical workflow. $J$ Contemp Brachytherapy. 2017;9(3):270-276.

72. Wiebe E, Easton H, Thomas G, Barbera L, D'Alimonte L, Ravi A. Customized vaginal vault brachytherapy with computed tomography imaging-derived applicator prototyping. Brachytherapy. 2015;14(3):380-384.

73. Miller DA, Richardson S, Grigsby PW. A new method of anatomically conformal vaginal cuff HDR brachytherapy. Gynecol Oncol. 2010;116(3):413-418.

74. Humphrey P, Cornes $\mathrm{P}, \mathrm{Al}-\mathrm{Booz} \mathrm{H}$. Vaginal vault brachytherapy in endometrial cancer: verifying target coverage with image-guided applicator placement. Br J Radiol. 2013;86(1023):20120428.

75. Richardson S, Palaniswaamy G, Grigsby PW. Dosimetric effects of air pockets around high-dose rate brachytherapy vaginal cylinders. Int $J$ Radiat Oncol Biol Phys. 2010;78(1):276-279.

76. Hassouna A, Bahadur YA, Constantinescu C. Assessment of air pockets in high-dose-rate vaginal cuff brachytherapy using cylindrical applicators. J Contemp Brachytherapy. 2014;6(3):271-275.

77. Onal C, Guler OC, Dolek Y. The impact of air pockets around the vaginal cylinder on vaginal vault brachytherapy. $\mathrm{Br} J$ Radiol. 2015;88(1047):20140694.

78. Maxwell A, Thiruthaneeswaran N, Lowe G, Wills R, Sripali S, Hoskin PJ. The dosimetric impact of air in vaginal vault brachytherapy. Brachytherapy. 2016;15(6):832-838. 
79. Patel S, Mehta KJ, Kuo HC, et al. Do changes in interfraction organ at risk volume and cylinder insertion geometry impact delivered dose in high-dose-rate vaginal cuff brachytherapy? Brachytherapy. 2016;15(2):185-190.

80. Owens KN, Patel HC, Yashar CM, Spanos WJ. Vaginal cuff brachytherapy for endometrial carcinoma: results of limiting vaginal coverage to one centimeter length. Brachytherapy. 2007;6:98-99.

81. Sorbe BG, Smeds AC. Postoperative vaginal irradiation with high dose rate afterloading technique in endometrial carcinoma stage I. Int J Radiat Oncol Biol Phys. 1990;18(2):305-314.

82. Kloetzer KH, Gunther R, Wendt T. Die Vaginalstumpf-Rezidivrate beim Endometriumkarzinom in Abhangigkeit des Zielvolumens der postoperativen HDR-Afterloading-Brachytherapie [The vaginal stump recurrence rate in endometrial carcinoma in relation to the target volume of postoperative HDR-afterloading brachytherapy]. Strahlenther Onkol. 1997;173(1):13-17.

83. Sabater S, Andres I, Jimenez-Jimenez E, et al. Rectal contrast increases rectal dose during vaginal cuff brachytherapy. Brachytherapy. 2016;15(1):35-39.

84. Sabater S, Sevillano M, Andres I, et al. Reduction of rectal doses by removal of gas in the rectum during vaginal cuff brachytherapy. Strahlenther Onkol. 2013;189:951-956.

85. Sabater S, Andres I, Gascon M, et al. Effect of rectal enemas on rectal dosimetric parameters during high-dose-rate vaginal cuff brachytherapy: a prospective trial. Strahlenther Onkol. 2016;192:248-253.

86. Andres I, Gutierrez-Perez M, Rodriguez-Vela MP, et al. The usefulness of fleet rectal enemas on high-dose-rate intracavitary cervical cancer brachytherapy. A prospective trial. J Contemp Brachytherapy. 2017;9(3):214-219

87. Guler OC, Onal C, Acibuci I. Effects of bladder distension on dose distribution of vaginal vault brachytherapy in patients with endometrial cancer. J Contemp Brachytherapy. 2015;6(4):371-376.

88. Kobzda JD, Cikowska-Wozniak E, Michalska M, Makarewicz R. Threedimensional dosimetry of the full and empty bladder in high dose rate vaginal cuff brachytherapy. Int J Gynecol Cancer. 2014;24(5):923-927.

89. Hoskin PJ, Vidler K. Vaginal vault brachytherapy: the effect of varying bladder volumes on normal tissue dosimetry. $\mathrm{Br} J$ Radiol. 2000;73(872):864-866.

90. Stewart AJ, Cormack RA, Lee H, et al. Prospective clinical trial of bladder filling and three-dimensional dosimetry in high-dose-rate vaginal cuff brachytherapy. Int J Radiat Oncol Biol Phys. 2008;72(3):843-848.

91. Russo JK, Armeson KE, Richardson S. Comparison of 2D and 3D imaging and treatment planning for postoperative vaginal apex highdose rate brachytherapy for endometrial cancer. Int J Radiat Oncol Biol Phys. 2012;83(1):e75-e80.

92. $\mathrm{Kim} \mathrm{H}, \mathrm{Kim} \mathrm{H}$, Houser C, Beriwal S. Is there any advantage to threedimensional planning for vaginal cuff brachytherapy? Brachytherapy. 2012;11(5):398-401.

93. Choo JJ, Scudiere J, Bitterman P, Dickler A, Gown AM, Zusag TW. Vaginal lymphatic channel location and its implication for intracavitary brachytherapy radiation treatment. Brachytherapy. 2005;4(3):236-240.

94. Li S, Aref I, Walker E, Movsas B. Effects of prescription depth, cylinder size, treatment length, tip space, and curved end on doses in high-dose-rate vaginal brachytherapy. Int J Radiat Oncol Biol Phys 2007;67(4):1268-1277.

95. Corso CD, Jarrio C, Nunnery EW, et al. Dosimetric and cost comparison of first fraction imaging versus fractional re-imaging on critical organ dose in vaginal cuff brachytherapy. Pract Radiat Oncol. 2013;3(4):256-262.

96. Zhou J, Prisciandaro J, Lee C, Schipper M, Eisbruch A, Jolly S. Single or multi-channel vaginal cuff high-dose-rate brachytherapy: is replanning necessary prior to each fraction? Pract Radiat Oncol. 2014;4(1):20-26.

97. Sabater S, Andres I, Sevillano M, Berenguer R, Machin-Hamalainen $\mathrm{S}$, Arenas M. Dose accumulation during vaginal cuff brachytherapy based on rigid/deformable registration vs. single plan addition. Brachytherapy. 2014;13(4):343-351.
98. Symon Z, Menhel J, Alezra D, Pfeffer MR. Individual fraction optimization vs. first fraction optimization for multichannel applicator vaginal cuff high-dose-rate brachytherapy. Brachytherapy. 2006;5(4): 211-215

99. Haie-Meder C, Potter R, Van Limbergen E, et al. Recommendations from Gynaecological (GYN) GEC-ESTRO Working Group (I): concepts and terms in 3D image based 3D treatment planning in cervix cancer brachytherapy with emphasis on MRI assessment of GTV and CTV. Radiother Oncol. 2005;74(3):235-245.

100. Sabater S, Pastor-Juan Mdel R, Berenguer R, et al. Analysing the integration of $\mathrm{MR}$ images acquired in a non-radiotherapy treatment position into the radiotherapy workflow using deformable and rigid registration. Radiother Oncol. 2016;119(1):179-184.

101. Owrangi AM, Jolly S, Balter JM, et al. Clinical implementation of MR-guided vaginal cylinder brachytherapy. J Appl Clin Med Phys. 2015;16(6):490-500.

102. Chapman CH, Prisciandaro JI, Maturen KE, et al. MRI-based evaluation of the vaginal cuff in brachytherapy planning: are we missing the target? Int J Radiat Oncol Biol Phys. 2016;95(2):743-750.

103. Small W, Beriwal S, Demanes DJ, et al. American Brachytherapy Society consensus guidelines for adjuvant vaginal cuff brachytherapy after hysterectomy. Brachytherapy. 2012;11(1):58-67.

104. Shih KK, Milgrom SA, Abu-Rustum NR, et al. Postoperative pelvic intensity-modulated radiotherapy in high risk endometrial cancer. Gynecol Oncol. 2013;128(3):535-539.

105. Ahamad A, D'Souza W, Salehpour M, et al. Intensity-modulated radiation therapy after hysterectomy: comparison with conventional treatment and sensitivity of the normal-tissue-sparing effect to margin size. Int J Radiat Oncol Biol Phys. 2005;62(4):1117-1124.

106. Ma DJ, Michaletz-Lorenz M, Goddu SM, Grigsby PW. Magnitude of interfractional vaginal cuff movement: implications for external irradiation. Int J Radiat Oncol Biol Phys. 2012;82(4):1439-1444.

107. Jhingran A, Salehpour M, Sam M, Levy L, Eifel PJ. Vaginal motion and bladder and rectal volumes during pelvic intensity-modulated radiation therapy after hysterectomy. Int J Radiat Oncol Biol Phys. 2012;82(1):256-262.

108. Aydogan B, Mundt AJ, Smith BD, et al. A dosimetric analysis of intensity-modulated radiation therapy (IMRT) as an alternative to adjuvant high-dose-rate (HDR) brachytherapy in early endometrial cancer patients. Int J Radiat Oncol Biol Phys. 2006;65(1): 266-273.

109. Low DA, Grigsby PW, Dempsey JF, et al. Applicator-guided intensity-modulated radiation therapy. Int J Radiat Oncol Biol Phys. 2002;52(5):1400-1406.

110. Cilla S, Macchia G, Sabatino D, et al. Applicator-guided volumetricmodulated arc therapy for low-risk endometrial cancer. Med Dosim. 2013;38(1):5-11.

111. Pedicini P, Caivano R, Fiorentino A, et al. Comparative dosimetric and radiobiological assessment among a nonstandard RapidArc, standard RapidArc, classical intensity-modulated radiotherapy, and 3D brachytherapy for the treatment of the vaginal vault in patients affected by gynecologic cancer. Med Dosim. 2012;37(4):347-352.

112. Pedicini P, Strigari L, Caivano R, et al. Local tumor control probability to evaluate an applicator-guided volumetric-modulated arc therapy solution as alternative of 3D brachytherapy for the treatment of the vaginal vault in patients affected by gynecological cancer. J Appl Clin Med Phys. 2013;14(2):4075.

113. Lanni TB Jr, Grills IS, Kestin LL, Robertson JM. Stereotactic radiotherapy reduces treatment cost while improving overall survival and local control over standard fractionated radiation therapy for medically inoperable non-small-cell lung cancer. Am J Clin Oncol. 2011;34(5):494-498.

114. Colombo N, Creutzberg C, Amant F, et al. ESMO-ESGO-ESTRO Consensus Conference on Endometrial Cancer: Diagnosis, Treatment and Follow-up. Int J Gynecol Cancer. 2016;26(1):2-30. 


\section{Publish your work in this journal}

Cancer Management and Research is an international, peer-reviewed open access journal focusing on cancer research and the optimal use of preventative and integrated treatment interventions to achieve improved outcomes, enhanced survival and quality of life for the cancer patient. The manuscript management system is completely online and includes a very quick and fair peer-review system, which is all easy to use. Visit http://www.dovepress.com/testimonials.php to read real quotes from published authors.

Submit your manuscript here: https://www.dovepress.com/cancer-management-and-research-journal 